\title{
Examining Digital Rukwangali and Education 4.0 in the context of Industry 4.0
}

\author{
Natalia S. Intja \\ nreino@unam.na \\ Lecturer in the Faculty of Education and Human Sciences, Department of Intermediate and \\ Vocational Education University of Namibia's Rundu Campus
}

\begin{abstract}
Industry 4.0 is a present-day inclination of mechanization and digitalization of industries. Hence, the effects and significance of Industry 4.0 are reflected in all facets of our lives. The tenacity of this article is to scrutinize the literature based on a scoping review method. A lack of digital culture, training, knowledge, and language also are challenges faced by Industry 4.0 while implementing its operations. Digital Rukwangali and Education 4.0 are also native language education employees' competencies of Industry 4.0. The author has reviewed the literature related to Digital languages, Education 4.0, and Industry 4.0 from various resources. Surprisingly, the results display that the studies conducted in these areas are so specific focusing only on digital English, education 4.0, and industry 4.0; no research article was identified that detailed the interconnections among Digital Rukwangali, Education 4.0, and Industry 4.0. From the scoping review, the study has identified the vacuums in the literature. In the final analysis, the study accomplishes that filling up the gaps and conducting research in these areas are useful to sort out a few of the challenges of Industry 4.0 and it recommends that in future, researchers conduct studies based on the interconnections of Digital Rukwangali and Education 4.0 for Industry 4.0.
\end{abstract}

Keywords: Digital Rukwangali; Education 4.0; Industry 4.0; ICT

\section{Introduction}

Cutting edge mechanical headways in instruction segments such as power point presentations, Moodle, Edmodo, panopto, creating persistent evaluation marks utilizing spread sheet to say some, 
influence educators' day by day schedules at work. In Namibia, particularly at the University of Namibia this wide zone has been introduced as Fourth Industrial Transformation, which is additionally known as Industry 4.0 (Shatrevich and Strautmane, 2015). Since Industry 4.0 proceeds to change the world, modern challenges emerge. From a worldwide viewpoint, the foremost imperative challenges whereas actualizing Industry 4.0 are found among the workers and directors: need of advanced culture and preparing, need of clear vision or back from directors, hazy financial benefits from ventures in advanced innovations, tall financial speculation prerequisites (Slusarczyk, 2018) and enlisting and creating modern ability, and common hesitance to alter by partners.

This study centers on one of the challenges confronted by Industry 4.0 that's an insufficient qualification of representatives counting a need of digital culture and preparing. The impacts of Industry 4.0 can be seen in our day-to-day lives and are reflected in all fields (Madrak-Grochowska, 2015; Wierzbicka, 2018). Technology-implemented up skilling within the instructing and learning prepare is known as Education 4.0, which is motivated by Industry 4.0 (Anggraeni, 2018). The Mechanical Transformation 4.0 gives the approach of the digital age, and claims that instructive institutions grasp an instruction transformation as well. Education 4.0 gives the idea of educating and learning advancement and employments data and innovation in its forms (Gulicheva, Osipova, \& Khabdullin 2017; Anggraeni 2018). As well as instructive institutions, people instructing in local dialects are considering embracing Education 4.0, but the challenge is there are no local e-language sources as well as the medium of communication on web in particularly the dialect in address, which is Rukwangali that can bolster the mechanical transformation 4.0.

This audit paper points to examine the scope and the advance of Advanced Rukwangali and Education 4.0 for Industry 4.0. The creator moreover centers and survey the affect and significance of Advanced Rukwangali and Education 4.0 for Industry 4.0; the thinks about related to these fields tend to supply a few curiously untimely ideas of Advanced Rukwangali and Instruction 4.0 for Industry 4.0 for the up and coming a long time. The objective of this study is to audit the chosen ranges utilizing the Scoping Survey method and also to motivate similar new zone researches in future. 


\section{The Scoping Review Protocol}

Wessels (2020) underscores that the scoping review protocol prescribes a transparent and rigorous approach to better understanding of a complex phenomenon. Moreover, is a type of knowledge synthesis that addresses an exploratory research question directed at mapping main ideas or concepts, research findings and gaps linked to a specified field or subject area through the systematic search, selection and synthesis of current state of knowledge. Deducing from the description thereof, this study espouses a Scoping Review method to analyse and review the literatures related to digital English, Education 4.0, and Industry 4.0 with the aim of deducing reputable findings to source/ inform the current study as a point of departure.

Literary works such as thesis, conference proceedings and journal articles that were surveyed through the scoping strategy and relating to advanced English, Instruction 4.0 and industry 4.0 were dissected. The dispersal is appeared in figure 1. As the literary works were surveyed, the taking after thought-provoking substances emerged. Firstly, advanced English and instruction 4.0 are partnered and they work generally well together, computerized English is the as it were favored dialect on web (Hariharasudan and Kot, 2018). Besides, since English have picked up a veritable worldwide status, it got to be the medium of communication in all angles of life, and those without English capability will not be able to memorize innovation and those who cannot take after the improvement of innovation will be cleared out behind and underestimated (Sukarno, 2019). Thirdly, Islam (2015) is of the sets that a dialect living in confinement debilitates it from getting impacted by innovation and find it hard to outlive within the cutting edge time.

Today's learning must include ICT which energizes self-regulated learning and solid positive character (Suherdi, 2019). With the point of making a feasible environment for instruction of future workers that will adjust with necessities of industry 4.0 (see the prerequisites of industry 4.0 in figure 2 underneath) which is crucial (Benesova, Hirman, Steiner and Tupa, 2019). To expand a point, unused occupations will be made that will be related with higher requests on information advanced advances and as it were tall qualified workers will be able to control these advances. The qualified representatives will get to be the key to victory for end of the associations and the 
instruction system will be exceptionally vital portion of concept industry 4.0. Halili, Sulaiman and Razar (2021) hypothesize that the unused skills, thinking skills and advanced literacy skills have to be implanted in educational programs and instructional method and instruction 4.0 could be a lifelong handle instead of fair centering on the classroom-oriented process. It is all around utilizing computerized innovations to form a compelling learning stage. Substantively, Ellahi, Khan and Shan (2019) stresses that without the colleges customarising their scholastics in line with instruction 4.0, there will be a more prominent shortage of required information and abilities. the ponder finds the holes in inquire about and persuades modern inquires about related to the scope and emphasizes the impacts and significance of Computerized Rukwangali and Instruction 4.0, which are the key calculate for Industry 4.0 and the impact of advanced marginalization of Rukwangali as a dialect and a medium of instruction in different modules instructed at the University of Namibia, Rundu campus which is additionally similarly required to embrace to the unused worldview of instruction 4.0.

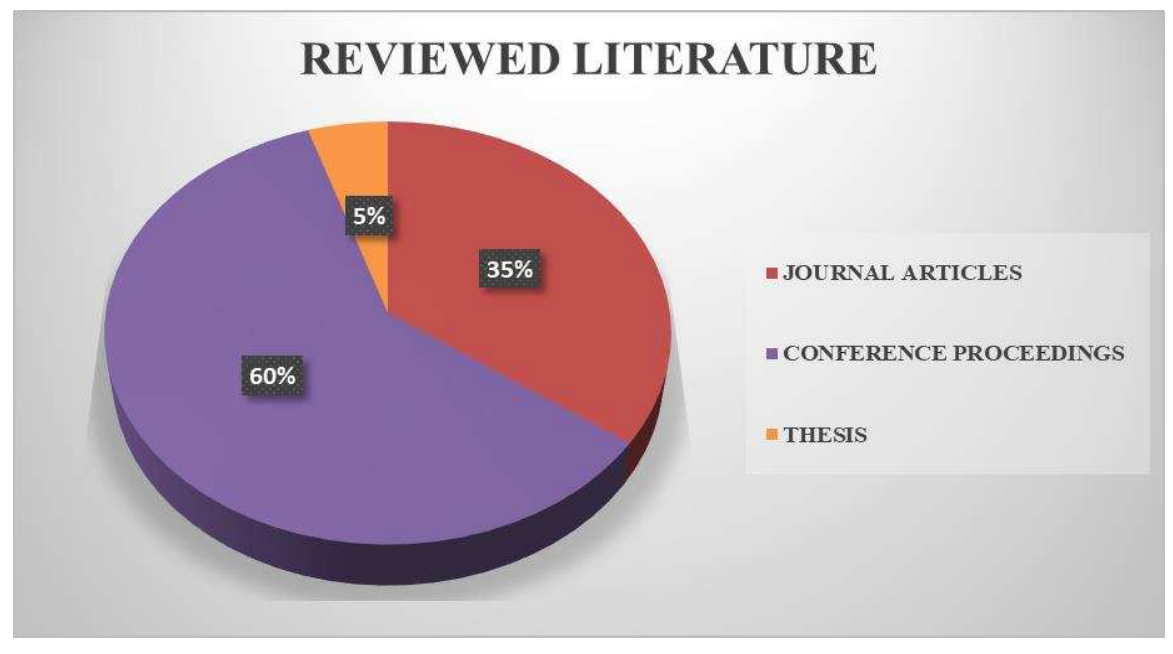

Figure 1. The dissemination of scoping reviewed literature 
ALIGNING INDUSTRY REQUIREMENTS WITH EDUCATION

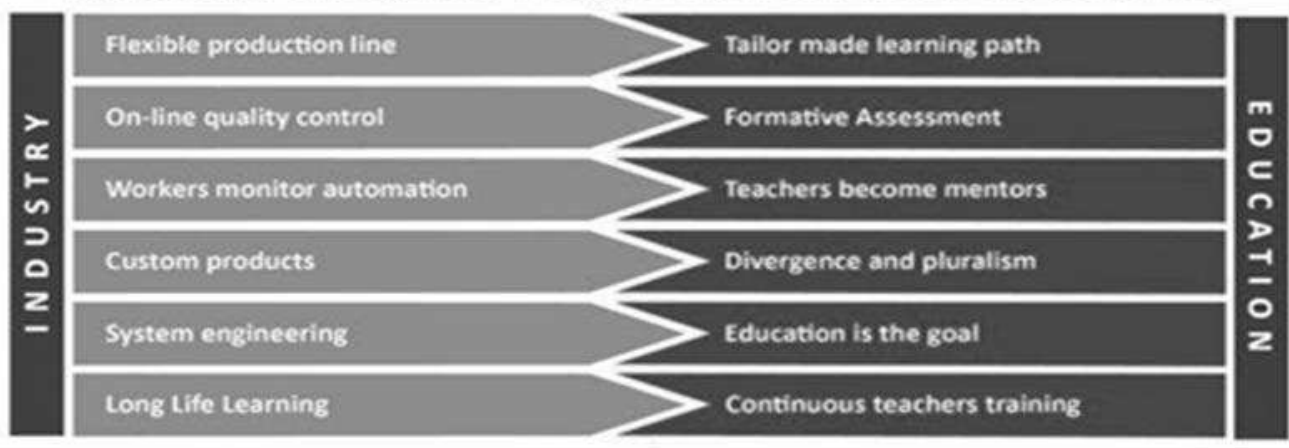

Figure 2. Aligning Industry Requirements with Education adopted from Benesova, et al (2019)

\section{Affiliation of Digital English and Education 4.0}

English is well known to be the official language of Namibia since 1990 when it got independent. It is used as the medium of instruction in both private and government schools and all the higher institutions of learning. One of the criteria for choosing English as the official language is feasibility as well as it's a language of wider communication and technology. It is against this background that the digital world is linked to this language. Besides, advances in instruction back educating and learning devices accessible within the advanced world and the dialects to get to the devices is English (Vanorsdale, 2017).

Education took a more organized approach, with understudies having their claim coordinate association to an assortment of distinctive data sources and this data are as it were gotten to through the medium of English. It is less demanding to adjust educating and learning strategies with the aptitudes required within the future by guaranteeing that colleges get ready their understudies for the fourth Mechanical Insurgency, one strategy of doing so is by empowering quickened farther learning where understudies learn hypothetical information remotely utilizing advanced implies, while guaranteeing any practical abilities are still learnt face-to-face.

\section{The Inclinations Related to Education 4.0}

Fisk (2017) points out nine patterns related to Instruction 4.0. the first one is that learning can be taken put anytime any place. e-Learning instruments offer extraordinary openings for farther, self- 
paced learning. Flipped classroom approach moreover plays a colossal part because it permits interactive learning to be done in lesson, whereas the hypothetical parts to be learned exterior the lesson time.

Second, learning will be personalized to person understudies. They will be presented to harder errands as it were after a certain dominance level is accomplished. More hones will be given on the off chance that the educates see a require in it. Positive fortifications are utilized to advance positive learning involvement and boost students' certainty approximately them possess scholastic capacities.

Third, understudies have a choice in deciding how they need to memorize. In spite of the fact that the learning results of a course are preset by the institutions/bodies in charge of the educational modules, understudies are still free to select the learning instruments or procedures that they lean toward. Among the alternatives that teachers can embrace to empower understudies to be inventive in their learning are mixed learning, flipped classroom and BYOD (Bring Your Own Device) approach.

Fourth, understudies will be uncovered to more project-based learning. Understudies are required to apply their information and skills in completing a handful of brief term ventures. By including within the ventures, they are practicing their authoritative, collaborative and time administration aptitudes which are valuable in their future scholarly careers.

Fifth, understudies will be uncovered to more hands-on learning through field encounter such as internships, mentoring ventures and collaborative ventures. The headway of the innovation empowers the learning of certain spaces successfully, hence making more room for procuring abilities that include human information and face-to-face interaction.

Sixth, understudies will be uncovered to information translation in which they are required to apply their hypothetical information to numbers and utilize their thinking abilities to create inductions based on rationale and patterns from given sets of information. The manual portion of 
numerical proficiency will end up insignificant as computers will perform the statistical investigation and foresee long term patterns.

Seventh, understudies will be evaluated in an unexpected way and the routine stages to survey understudies may have gotten to be insignificant or inadequately. Students' truthful information can be surveyed amid the learning prepare, whereas the application of the information can be tried when they are working on their ventures within the field.

Eighth, students' supposition will be considered in planning and upgrading the educational programs. Their inputs offer assistance the educational modules originators keep up educational programs contemporariness, up-to date and convenience.

Lastly, understudies will end up more free in their claim learning, hence constraining instructors to expect a modern part as facilitators who will direct the understudies through their learning handle. The nine patterns of Instruction 4.0 move the major learning obligations from the teaches to the learners. Teaches ought to play their parts to back the move and ought to never consider it a risk to the customary educating profession.

\section{Education 4.0 at the University of Namibia}

Hussin (2018) says that the infiltration of technologies keeps evolving and transforming the science of teaching and the setting of the learning process. In fact, we should expect more changes in the future. Some of the common changes that have been embraced by the University of Namibia includes lecturers delivering lessons virtually using the BigBlueButton, Panopto, Zoom and Podcast recorders to mention a few, lecturers posting assignment questions on Moodle and students submitting answered assignments on Moodle and taking up online tests via Moodle, lecturers extracting continuous assessment marks which are readily generated by the Moodle system in a form of a grading book, uploading learning materials for students on UNAM portal and Moodle, overriding students to take up missed or failed assessments, entering of marks on the lecturer's iEnabler, accessing pay slips on the lecturer's iEnabler using a personalized password, getting 
linked to modules taught online, requesting to be linked to a module using the ticketing system and attending meetings, workshops and conferences virtually.

In as much as Instruction 4.0 is grasped at the University of Namibia, innate dialects offered at the institution are carefully marginalized. Usually since the Moodle Learning Administration Framework is outlined within the medium of English and the innate dialect speakers are anticipated to instruct their modules utilizing the same LMS. The challenge is that modules such as Rukwangali Dialect Instruction, which may be a module instructed within the dialect beneath ponder which is Rukwangali have destinations of conveying the subject substance in Rukwangali, enhancing students' sentence structure, semantics, morphology and phonology and writing, but it is an obstacle since the initiation of virtual learning as understudies got to get to the LMS within the medium of English and learn the substance as well as write tests within the medium of Rukwangali. From now on, the choice of "True or False" as a question sort is composed in English, since the alternative is as of now imbedded within the framework and when the lecturer transfers the questions on Moodle utilizing this question sort they are cleared out with no alternative but to set the questions in Rukwangali and take off the reply alternatives as "True or False" rather than "Yimo ndi kapisi Yimo". And when the understudies take up the test they complain to the teacher that they feel that they are not learning Rukwangali but or maybe Rukwangali and English as a module.

With all the pickles of Instruction 4.0 the college is still anticipated to continue on with online educating and learning whereas guaranteeing that challenges experienced are considered and moderated. Dunwill (2016) anticipated that a normal classroom will have a gigantic alter within the format, virtual learning will alter the instructive scene and adaptable assignments will suit different learning styles. Comparative change has already taken put within the instruction setting in Namibia. Format of the classroom has steadily changed from neat rows and chairs to adaptable seating courses of action within the comfort homes empowering for both person and collaborative working environments. Understudy assignments are not submitted as hard duplicates. Elective appraisals have been presented to suit different learning styles. Venture papers, e-portfolios within the workforce of instruction are among the elective appraisals being practiced nowadays. 
Online teaching and learning seems rather new to many lecturers and students at the university of Namibia. Help is still sought for both lecturers and students to navigate through this trying time of Covid-19. Despite this, the following table displays ten fundamental digital skills for lecturers at the university of Namibia.

Table 1. Ten Fundamental Digital Skills for Lecturers at the University of Namibia

\begin{tabular}{|c|c|}
\hline Digital Skills & Tools to Use \\
\hline 1. Record lessons virtually & $\begin{array}{l}\text { 1. Podcasts, Panopto, } \\
\text { Zoom, BigBlueButton }\end{array}$ \\
\hline 2. Create engaging presentations & 2. Google Slides \\
\hline 3. Create digital portfolios & 3. Google sites \\
\hline 4. Create non-traditional quizzes & 4. Moodle \\
\hline 5. Uploading learning materials & 5. Portal and Moodle \\
\hline 6. Assessing assignments & 6. Moodle \\
\hline 7. Entering of students' marks & 7. Lecturer's iEnabler \\
\hline 8. Overriding students & 8. Moodle \\
\hline 9. Extracting class lists of specific modules & 9. Lecturer's iEnabler \\
\hline 10. Attending meetings, conferences or workshops & 10. Zoom \\
\hline
\end{tabular}

\section{The Significance of Advanced Rukwangali within the computerized age}

English is considered as the language of communication in academia and the language of the internet, Rukwangali should equally be developed to be the language of the internet because uses of the internet accelerate the speed of globalization. Digital English can be defined as the medium and electronic version of English in the digital environment (Benesova, et al. 2019). Deducing from this definition, Digital Rukwangali in this paper refers to the medium and electronic version of Rukwangali in the digital environment. 
Just like the way English has gained popularity, Rukwangali could as well be popular by ensuring that search engines are designed in Rukwangali. For this to be evitable, scholarly publications in the language of Rukwangali need to be high which is low or equally to zero as of current. African languages particularly Rukwangali seem to be more of a research topic or point of debate than a broad communication medium in the cyberspace (Sukarno, 2019). Another constraint points to the reluctance of foreign and local sponsors to invest in ICTs and African languages (Dia, 2014).

The internet is a crucial tool in the modern era, thus digitalizing the language of Rukwangali may uplift the status of the language, enabling researchers to research in Rukwangali and publish in the same language. Observably, in researches in Namibia are only written in the medium of English. Digitalizing the Rukwangali language may enable lecturers and students to navigate the online teaching and learning platforms in the language of the module content. Below is the chart showing top 10 languages of the internet as of January 2020.

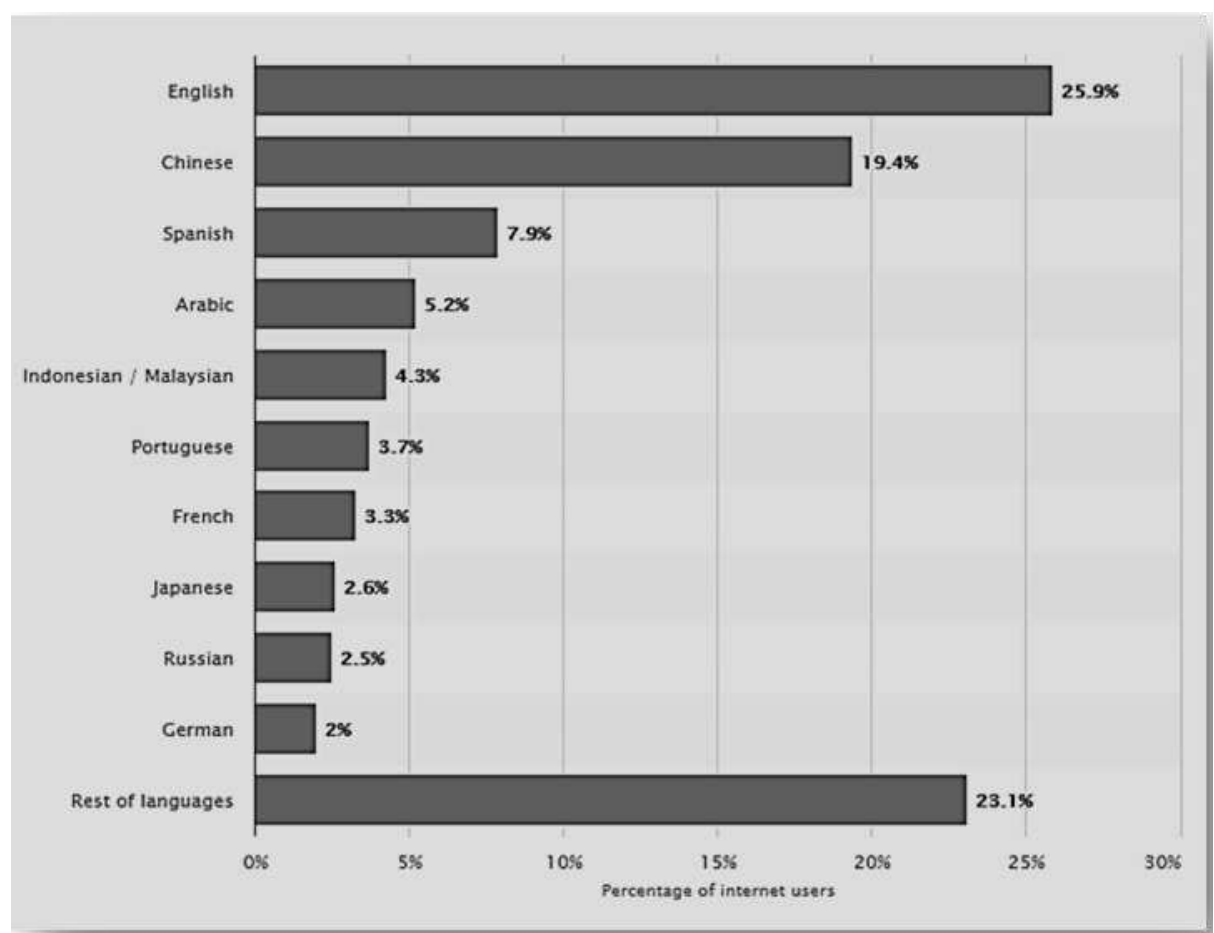

Figure 3. Languages used on the Internet as of January 2020, adopted from Johnson (2021) 
As of January 2020, English was the foremost well-known dialect online, speaking to 25.9 percent of around the world web clients. Chinese was positioned moment with a 19.4 percent share. The best ten dialects accounted for 76.9 percent of worldwide web clients. The huge share of Chinese-language substance is due to the truth that China is by far the nation with the foremost web clients around the world. This chart still appears and demonstrate that the dialect in address is still not the language of the web and it still however to get that status.

\section{Identified Gaps in Writing and Justifications}

Studies conducted in the field of Digital English, Education 4.0 and Industry 4.0 were analysed with the researcher's core goal of finding the gaps and reviewing the available literatures. However, the studies conducted in those areas are so specific focusing only to the context of Digital English, Education 4.0 and Industry 4.0, no research has been identified on analysing the interconnections among Digital Rukwangali, Education 4.0 and Industry 4.0. Moreover, no research was done to find ways on digitalizing Rukwangali in the education fraternity and until to date there are no scholarly publications in the language in question and no search engines on internet provide sources in Rukwangali. Due to increased demand and the need to teach in the medium of Rukwangali at the University of Namibia and the impact Covid-19 has brought to forcefully move to online teaching and learning, a more complete body of research is needed in the area of Digital Rukwangali and Education 4.0 for Industry 4.0. Thus the research gaps are identified by the researcher as follow:

From the studies, it is evident that the students have been conducted among Education 4.0 and English language learning and they are linked to each other and are implemented in many places. However, there is a gap in the interconnection of Rukwangali language learning and Education 4.0 and there is a dearth of literature in the language in question. No research was conducted to find out the importance of Digital Rukwangali and Industry 4.0. There is a need for future research on the interconnection of Digital Rukwangali and Education 4.0 for Industry 4.0. It is clear that the lack of training or knowledge is one of the most tangible challenges while implementing the Industry 4.0. 


\section{Results, Discussions and Conclusions}

The study has recognized three outcomes after a cautious examination of already conducted ponders related to the areas of Digital English, Instruction 4.0 and Industry 4.0. There's no evidence that there's an interconnection between Digital English and Education 4.0. The discoveries of Hariharasudan, et al. (2018) concludes that no inquiries recognized the nitty gritty that interconnects Digital Rukwangali and education 4.0 and filling up the gaps and conducting research in these areas are useful to sort out a number of challenges of Industry 4.0. The ponders surveyed too show that there's a dearth of literature in ways of digitalizing Rukwangali within the instruction society and the search engines do not have Rukwangali as a dialect of the web which lead to its digital marginalization within the internet.

The study suggests that the University of Namibia ought to explore for procedures to form the Moodle stage user-friendly by the teachers and understudies of Namibian dialects, by ensuring that the Learning Administration Framework is grown within the local dialects. Including to that, the university should roll-out more locks in preparing sessions to prepare its scholastics on how to utilize the Moodle stage, particularly setting tests and assignments. Understudies may moreover require preparing on how to get to and utilize Moodle and UNAM Portal.

\section{Acknowledgements}

All the glory be to my Prince of Peace for all the mercies he bestowed in me during the write-up of this paper and to my children Gracious and Ryan and husband for according me all the time and space I needed to research. In addition, the researcher extends her major appreciation to the International Journal of Research Publications for accepting my manuscript for publication. This is a breakthrough.

\section{References}

Anggraeni, C., W. (2018). Promoting Education 4.0 in English for Survival Class: What are the Challenges? Metathesis-Journal of English Language, Literature, and Teaching, 2,12-24. 
Benesova, A., Hirman, M., Steiner, F. \& Tupa, J. (2019). Requirements for Education 4.0 and Study Programs within Industry 4.0, Proceedings of the International Conference on Industrial Engineering and Operations Management Pilsen, Czech Republic, July 23-26, 2019.

Dia, I., A. (2014). African languages, and information communication technologies and development. International Journal of the Sociology of Language (IJSL), 225, 113-130.

Dunwill, E. (2016). 4 changes that will shape the classroom of the future: Making education fully technological. Accessed from https://elearningindustry.com/4-changes-will-shapeclassroom-of-the-future-making-education-fully-technological.

Ellahia, R., M., Khan, M., U., A., \& Shah, A. (2019). Redesigning Curriculum in line with Industry 4.0, Proceedings of The 2nd International Conference on Emerging Data and Industry 4.0 (EDI40) April 29 - May 2, 2019. Leuven, Belgium: Elsevier B.V. Publishing.

Fisk, P. (2017). Education 4.0 ... the future of learning will be dramatically different, in school and throughout life. Retrieved from http://www.thegeniusworks.com/2017/01/future-educationyoung-everyone-taught-together

Gulicheva, E., Lisin, E., Osipova, M., \& Khabdullin, A. (2017). Leading factors in the formation of innovative education environment. Journal of International Studies, 10, 129 - 37.

Halili, S., H., Sulaiman, S., Sulaiman, H., \& Razak, R. (2021). Embracing industrial revolution 4.0 in universities, proceedings of the Annual Conference on Computer Science and Engineering Technology (AC2SET) 2021. Malaysia: IOP Publishing. 
Hariharasudan, A., \& Kot, S. (2018). A Scoping Review on Digital English and Education 4.0 for Industry 4.0. Journal of Social Sciences, 7, 1 - 13.

Hussin, A., A. (2018). Education 4.0 Made Simple: Ideas for Teaching. International Journal of Education \& Literacy Studies, 6(3),92-98.

Islam, M. S. (2015). Pursuing Alternative Development: Indigenous People, Ethnic Organization and Agency. New York: Palgrave Macmillan.

Johnson, J. (2021, January 27). Most common languages used on the internet as of January 2020, by share of internet users. Statista. https://www.statista.com/statistics/262946/share-of-themost-common-languages-on-the-internet/

Madrak-Grochowska, M. (2015). The Knowledge-based Economy as a Stage in the Development of the Economy. Oeconomia Copernicana, 6, 7-21.

Shatrevich, V., \& Strautmane, V. (2015). Industrialisation Factors in Post-industrial Society. Entrepreneurship and Sustainability, 3, 157-72.

Slusarczyk, B. (2018). Industry 4.0-Are We Ready? Polish Journal of Management Studies, 17, $232-48$.

Suherdi, D. (2019). Teaching English in the industry 4.0 and disruption era: Early lessons from the implementation of SMELT I 4.0 DE in a senior high lab school class. Indonesian Journal of Applied Linguistics, 9(1), 67-75. http://ejournal.upi.edu/index.php/IJAL/article/view/16418 
Surkano (2019). Saving and preparing the Indigenous Communities to Face the Industrial Revolution 4.0 Era through Local Wisdom and English Language Mastery, proceedings of the 1st International Conference on Education, Social Sciences and Humanities (ICESSHum 2019). Yogyakarta, Indonesia: Atlantis Press Publishing.

Vanorsdale, C. (2017). Communicative Language Teaching in E-Learning: How Confident are the Instructors? Paper presented at the E-Learn: World Conference on E-Learning in Corporate, Government, Healthcare, and Higher Education, Vancouver, BC, Canada, October 17; pp. 489-93.

Wessels, L. (2020). How South African Universities Can Contribute to Preparing the Future Workforce for the Fourth Industrial Revolution. Master's thesis, Stellenbosch University.

Wierzbicka, W. (2018). Information Infrastructure as a Pillar of the Knowledge-based Economy-An Analysis of Regional Differentiation in Poland. Equilibrium. Quarterly Journal of Economics and Economic Policy, 13,123-39. 